\title{
MicroRNA-421-targeted PDCD4 regulates breast cancer cell proliferation
}

\author{
YIWEI WANG ${ }^{1}$, ZIPENG LIU ${ }^{2}$ and JIAN SHEN ${ }^{3}$ \\ ${ }^{1}$ Tianjin First Center Hospital, Tianjin 300192; ${ }^{2}$ Hanzhong Central Hospital, Hanzhong, Shaanxi 723000; \\ ${ }^{3}$ The Second Affiliated Hospital of Xi'an Medical University, Xi'an, Shaanxi 710038, P.R. China
}

Received March 7, 2018; Accepted September 26, 2018

DOI: $10.3892 /$ ijmm.2018.3932

\begin{abstract}
MicroRNAs (miRNAs) are expressed aberrantly in various types of cancer, and negatively regulate the expression of target genes which may be useful in therapeutic strategies in several biological processes. In the present study, the expression levels and the effects of miRNA (miR)-421 in breast cancer tissues and MCF-7 and MDA-MB-231 cells were evaluated to elucidate therapeutic targets in breast cancer cells. The putative targets of miR-421 were predicted by bioinformatics approaches, and the expression levels of miR-421 were measured in MCF-7 and MDA-MB-231 cells by reverse transcription-quantitative polymerase chain reaction analysis following miR-421 knockdown. The rates of cell proliferation, migration capacity, invasiveness and apoptosis were determined in miR-421 inhibitor-transfected MCF-7 and MDA-MB-231 cells. The expression levels of target proteins regulated by miR-421 in MCF-7 and MDA-MB-231 cells were analyzed by western blot analysis. miR-421 was increased significantly in breast cancer tissues and cells, and was regulated by miR-421 antisense oligonucleotides. The knockdown of miR-421 in MCF-7 and MDA-MB-231 cells decreased cell proliferation, migration capacity and invasiveness, and promoted apoptosis compared with control groups. The expression of target protein programmed cell death 4 (PDCD4) were decreased in MCF-7 and MDA-MB-231 cells transfected with miR-421 inhibitors. These results suggested a correlation between miR-421 and PDCD4, and physiological functions of breast cancer cells, suggesting that miR-421 may be a potential strategy in the therapy of breast cancer.
\end{abstract}

\section{Introduction}

Breast cancer (BC) is one of the most common types of cancer and main causes of cancer-associated mortality in women worldwide (1). The onset of BC typically occurs between 20 and

Correspondence to: Dr Jian Shen, The Second Affiliated Hospital of Xi'an Medical University, 33 East China Road, Xi'an, Shaanxi 710038, P.R. China

E-mail: shenjian20188@126.com

Key words: breast cancer, microRNA-421, programmed cell death 4
60 years of age, and the incidence of this disease has markedly increased in China in recent years (2). Due to improvements in diagnostic and therapeutic methods, including surgery, radiotherapy, chemotherapy, hormone therapy, immunotherapy, stem cell therapy and gene silencing, the mortality rate of BC has markedly decreased (3-5). However, the molecular mechanisms of BC remain to be fully elucidated. It is well known that an accumulation of hereditary and epigenetic changes, including oncogene activation, tumor suppressor gene inactivation (6), changes in intercellular complex signal networks, microenvironment $(7,8)$ and epigenetic changes $(9,10)$ contribute to the formation of malignant tumors. An increasing number of studies have indicated that epigenetic changes may represent important events in the pathogenesis of BC (11-13), and that gene silencing at the post-transcriptional level may be an important epigenetic change (14,15).

Although prognostic microRNAs (miRNAs), including miRNA (miR)-21, miR-489 and miR125b, have been identified in $\mathrm{BC}(16)$, the underlying pathways that regulate the invasiveness of $\mathrm{BC}$ remain to be elucidated. miRNAs are able to bind to their target mRNAs to induce degradation or suppress translation (17). miRNAs are involved in cellular processes, including cell differentiation, cell proliferation, apoptosis and tumor inhibition (18-20). Previous studies have shown that miRNAs are critical in the development and progression of $\mathrm{BC}$, for example, by functioning as tumor suppressors or oncogenes.

miR-421 is a tumor suppressor that is aberrantly expressed in several types of cancer. For example, miR-421 inhibits the proliferation and metabolism of prostate cancer cells by targeting Cullin 4B (21) and suppresses BC metastasis by targeting metastasis associated 1 (22). Furthermore, the higher positive detection rate of miR-421 compared with serum carcino-embryonic antigen in gastric cancer indicates that miR-421 may serve as a superior diagnostic marker (23). A number of studies have reported that miR-421 acts as an oncogene, however, its underlying mechanisms in $\mathrm{BC}$ remain to be fully elucidated.

The aim of the present study was to investigate the regulatory role of miR-421 in $\mathrm{BC}$ and the underlying molecular mechanism responsible.

\section{Materials and methods}

Patients. A total of $52 \mathrm{BC}$ tissue samples were collected from 52 patients (52 females; 43-68 years old; mean age 
$55.6 \pm 12.5$ years) histologically diagnosed with BC between 2015 and 2017 at the Second Affiliated Hospital of Xi'an Medical University (Xi'an, China). In addition, 52 normal tissue samples (52 females; 44-74 years old; mean age $50.2 \pm 10.4$ years) were obtained from the same hospital. All protocols were approved by the Ethics Committee of the Second Affiliated Hospital of Xi'an Medical University and written informed consent was provided by all participants. The clinical characteristics of the patients with $\mathrm{BC}$ are summarized in Table I.

Cell culture. The MCF-7 and MDA-MB-231 BC cells, in addition to the normal Hs578bst cell line, were purchased from the Cell Resource Center of the Shanghai Academy of Sciences (Shanghai, China). The cells were cultured in an atmosphere containing $5 \% \mathrm{CO}_{2}$ at $37^{\circ} \mathrm{C}$ in DMEM supplemented with $10 \%$ FBS (both from Hyclone; GE Healthcare Life Sciences, Logan, UT, USA), $100 \mathrm{U} / \mathrm{ml}$ penicillin and $100 \mathrm{mg} / \mathrm{ml}$ streptomycin.

Reverse transcription-quantitative polymerase chain reaction (RT-qPCR) analysis. Total RNA was extracted from the BC tissues, MCF-7 cells and MDA-MB-231 cells using TRIzol (Invitrogen; Thermo Fisher Scientific, Inc., Waltham, MA, USA) and was quantified using a photometer. cDNA was synthesized using M-MLV reverse transcriptase (Invitrogen; Thermo Fisher Scientific, Inc.) according to the manufacturer's protocol. All PCR primers were designed and synthesized by Invitrogen; Thermo Fisher Scientific, Inc. qPCR analysis was performed according to the manufacturer's protocol. The reaction mixture comprised the following: cDNA $(0.5 \mu \mathrm{l})$, forward primer $(0.5 \mu \mathrm{l})$, reverse primer $(0.5 \mu \mathrm{l}), 2.5 \mathrm{mM}$ dNTPs $(2 \mu \mathrm{l}), 10 \mathrm{U} / \mu \mathrm{l}$ DNA polymerase $(0.5 \mu \mathrm{l}), 5 \mathrm{X}$ buffer (4 $\mu \mathrm{l})$ and $\mathrm{ddH}_{2} \mathrm{O}(12 \mu \mathrm{l})$. The thermocycling conditions were as follows: 35 cycles at $95^{\circ} \mathrm{C}$ for $5 \mathrm{~min}, 95^{\circ} \mathrm{C}$ for $15 \mathrm{sec}$ and $56^{\circ} \mathrm{C}$ for $40 \mathrm{sec}$. U6 was used as an internal reference. The primers used were as follows: miR-421, forward, 5'-ACACTC CAGCTGGGATCAACAGACATTAATTG-3' and reverse, 5'-TGGTGTCGTGGAGTCG-3'; U6, forward, 5'-CTCGCT TCGGCAGGACA-3' and reverse, 5'-AACGCTTCACGA ATTTGCGT-3'; PDCD4, forward, 5'-TCTGGGAAAGGA AGGGGACTAC-3' and reverse, 5'-TTCATAAACACAGTT CTCCTGGTCAT-3'; U6 forward, 5'-CTCGCTTCGGCAGCA CA-3' and reverse, 5'-AACGCTTCACGAATTTGCGT-3'. The results were quantified using the $2^{-\Delta \Delta \mathrm{Cq}}$ method (24).

Immunohistochemistry. Tissues slides $(1.2 \times 1.2 \mathrm{~cm})$ were incubated with primary PDCD4 antibody (dilution 1:600; cat. no. PA5-20309; Invitrogen; Thermo Fisher Scientific, Inc.) at $37^{\circ} \mathrm{C}$ for $30 \mathrm{~min}$ and were washed twice with cold PBS. Subsequently, the slides were incubated with horseradish peroxidase-conjugated goat anti-rabbit IgG $(\mathrm{H}+\mathrm{L})$ secondary antibody (dilution 1:100; cat. no. 31460; Invitrogen; Thermo Fisher Scientific, Inc.) for $30 \mathrm{~min}$ at room temperature. The slides were developed with 3,3'-diaminobenzidine and the nuclei were lightly stained with hematoxylin. The expression of PDCD4 was evaluated by observing at least five fields of the slides under an inverted non-confocal microscope (CKX53 type, 4000K LED light; Olympus Corporation, Tokyo, Japan), with at least 100 cells per field assessed.
Cell transfection. miR-421 mimics, miR-421 inhibitors, mock miRNAs and the luciferase reporter plasmid were designed and synthesized by Invitrogen; Thermo Fisher Scientific, Inc. The MCF-7 and MDA-MB-231 cells were transfected with miR-421 mimics, miR-421 inhibitors or mock miRNAs using Lipofectamine ${ }^{\circledR} 2000$ (Invitrogen; Thermo Fisher Scientific, Inc.) according to the manufacturer's protocol.

Western blot analysis. The cells were lysed and proteins were quantified using a BCA assay. The proteins (25 $\mu \mathrm{g} /$ lane) were separated by $10 \%$ SDS-PAGE and transferred onto PVDF membranes (Bio-Rad Laboratories, Inc., Hercules, CA, USA). The membranes were incubated with primary antibodies against PDCD4 (dilution 1:600; cat. no. PA5-20309; Invitrogen; Thermo Fisher Scientific, Inc.) and GAPDH (dilution 1:800; cat. no. MA5-15738; Invitrogen; Thermo Fisher Scientific, Inc.) at $37^{\circ} \mathrm{C}$ for $30 \mathrm{~min}$. The membranes were subsequently incubated with horseradish peroxidase-conjugated goat anti-rabbit IgG $(\mathrm{H}+\mathrm{L})$ secondary antibody. The band intensities were evaluated using ImageJ 1.47 software (National Institutes of Health, Bethesda, MD, USA).

Luciferase reporter assay. A search for putative targets of miR-421 was performed with TargetScan Human7.2 software. Target genes of miR-421 were predicted by TargetScan (http://www.targetscan.org/vert_71/). To determine whether PDCD4 is a direct target gene of miR-421, luciferase reported assays were performed. The luciferase reporter plasmids pGL3-PDCD4 3'UTR wild-type (WT) and pGL3-PDCD4 3'UTR mutant type (Mut) were designed and synthesized by Invitrogen; Thermo Fisher Scientific, Inc. The MCF-7 and MDA-MB-231 cells were seeded in 24-well plates and cultured until they reached $40 \%$ confluence. The cells were then transfected with miR-421 mimics, inhibitors or mock miRNA using Lipofectamine ${ }^{\circledR} 2000$ according to the manufacturer's protocol. After $24 \mathrm{~h}$ incubation at $37^{\circ} \mathrm{C}$, the cells were harvested and luciferase activity was assessed using the Dual-Luciferase Reporter Assay system (Promega Corporation, Madison, WI, USA). Each experiment was performed in triplicate.

Cell proliferation assay. Following transfection, the proliferation of the MCF-7, MDA-MB-231 and Hs578bst cells was determined using Cell Counting Kit-8 (Beijing Solarbio Science \& Technology Co., Ltd., Beijing, China) according to the manufacturer's protocol. For each experimental group, six duplicate wells were assessed.

Cell migration and invasion assays. The MCF-7 and MDA-MB-231 cells were cultured and treated as described above, following which cell migration and invasion were assessed using Transwell assays. The filters (Corning Incorporated, Corning, NY, USA) were washed in serum-free DMEM and placed into 24-well plates. The lower Transwell chamber contained DMEM supplemented with $10 \%$ FBS. A total of $3 \times 10^{4} \mathrm{BC}$ cells were seeded in the upper chamber with $200 \mu \mathrm{l}$ DMEM supplemented with $0.1 \%$ bovine serum albumin (BD Biosciences, Franklin Lakes, NJ, USA), with a $2 \mathrm{mg} / \mathrm{ml}$ Matrigel-coated membrane containing 8-m pores. The Transwell chamber was subsequently incubated at $37^{\circ} \mathrm{C}$ in an atmosphere containing $5 \% \mathrm{CO}_{2}$ for $24 \mathrm{~h}$. Following incubation, any cells 
Table I. Association between clinicopathological factors and miR-421 levels.

Level of miR-421

\begin{tabular}{|c|c|c|c|c|}
\hline \multirow{2}{*}{ Clinicopathological factor } & \multirow[b]{2}{*}{ No. of patients $(n=52)$} & & & \multirow[b]{2}{*}{ P-value } \\
\hline & & High, n (\%) (n=28) & Low, n $(\%)(\mathrm{n}=24)$ & \\
\hline Age (years) & & & & $<0.001$ \\
\hline$<55$ & 20 & $11(39.28)$ & $9(37.50)$ & \\
\hline$\geq 55$ & 32 & $17(60.71)$ & $15(62.50)$ & \\
\hline Pathological stage & & & & $<0.001$ \\
\hline $\mathrm{I}+\mathrm{II}$ & 38 & $20(71.4)$ & $18(75.00)$ & \\
\hline III+IV & 14 & $8(28.57)$ & $6(25.00)$ & \\
\hline Histological grade & & & & $<0.001$ \\
\hline $\mathrm{I}+\mathrm{II}$ & 34 & $18(64.28)$ & $16(66.66)$ & \\
\hline $\mathrm{III}+\mathrm{IV}$ & 18 & $10(35.71)$ & $8(33.33)$ & \\
\hline Lymph node status & & & & $<0.001$ \\
\hline Negative & 32 & $16(57.14)$ & $16(66.66)$ & \\
\hline Positive & 20 & $12(42.85)$ & $8(33.33)$ & \\
\hline ER status & & & & 0.069 \\
\hline Negative & 26 & $15(53.57)$ & $11(45.83)$ & \\
\hline Positive & 26 & $13(46.42)$ & $13(54.16)$ & \\
\hline PR status & & & & 0.053 \\
\hline Negative & 30 & $17(60.71)$ & $13(54.16)$ & \\
\hline Positive & 22 & $11(39.28)$ & $11(45.83)$ & \\
\hline HER-2 status & & & & 0.074 \\
\hline Negative & 40 & $21(75.00)$ & $19(79.16)$ & \\
\hline Positive & 12 & $7(25.00)$ & $5(20.83)$ & \\
\hline Ki67 & & & & 0.081 \\
\hline$<15 \%$ & 29 & $17(60.71)$ & $12(50.00)$ & \\
\hline$\geq 15 \%$ & 23 & $11(39.28)$ & $12(50.00)$ & \\
\hline
\end{tabular}

P-values were calculated by $\chi^{2}$ test, Fisher's exact test, Student's t-test or Mann-Whitney U tests. $\mathrm{P}<0.05$ was considered statistically significant. miR, microRNA; ER, estrogen receptor; PR, progesterone receptor; HER-2, human epidermal growth factor receptor-2.

remaining on the upper membrane surface were removed with a cotton swab, whereas cells on the lower surface of the membrane were fixed in $10 \%$ formalin at room temperature for $30 \mathrm{~min}$ and stained with $0.5 \%$ crystal violet. Images were captured of six randomly selected fields of view using an inverted microscope (Nikon Corporation, Otsu, Japan) at x200 magnification. For the migration assay, transfected cells $\left(2 \times 10^{4}\right.$ cells/chamber $)$ were seeded in the top chamber, as above, without Matrigel. After $24 \mathrm{~h}$, the migrated cells were lysed in glacial acetic acid and the solution was transferred to a 96-well culture plate. Colorimetry was performed at $560 \mathrm{~nm}$ to determine the optical density. Each experiment was performed in triplicate.

Statistical analysis. All results were analyzed using SPSS 16.0 (SPSS, Inc., Chicago, IL, USA) and GraphPad 5.0 (GraphPad Software, Inc., La Jolla, CA, USA). $\chi^{2}$ or Fisher's exact test was used to compare categorical variables as appropriate. Student's t-test, Mann-Whitney U test and one-way analysis of variance with Tukey's post hoc test were used to compare continuous data. $\mathrm{P}<0.05$ was considered to indicate a statistically significant difference.

\section{Results}

Patient characteristics. To investigate the expression of miR-421 in patients with BC with different clinicopathological features, 52 patients with $\mathrm{BC}$ were divided into two groups (28 in the miR-421 high expression group and 24 in the low expression group). Patients' characteristics are summarized in Table I. No significant differences were observed in clinicopathological factors, including estrogen receptor status, progesterone receptor status, human epidermal growth factor receptor-2 status, and $\mathrm{Ki}-67$ status, between the miR-421 high expression group and miR-421 low expression group. However, an older age at diagnosis was associated with a high expression of miR-421 in patients with $\mathrm{BC}(\mathrm{P}<0.001)$. The pathological stage, histological grade and lymph node status were also closely associated with the expression of miR-421 $(\mathrm{P}<0.001)$.

Protein expression of PDCD4 in BC tissues. The protein expression of PDCD4 in tissues of patients with $\mathrm{BC}$ were analyzed by immunohistochemistry, although only 15 pairs of 
A

Case 1

Case2

Case3

Case 4

Case5
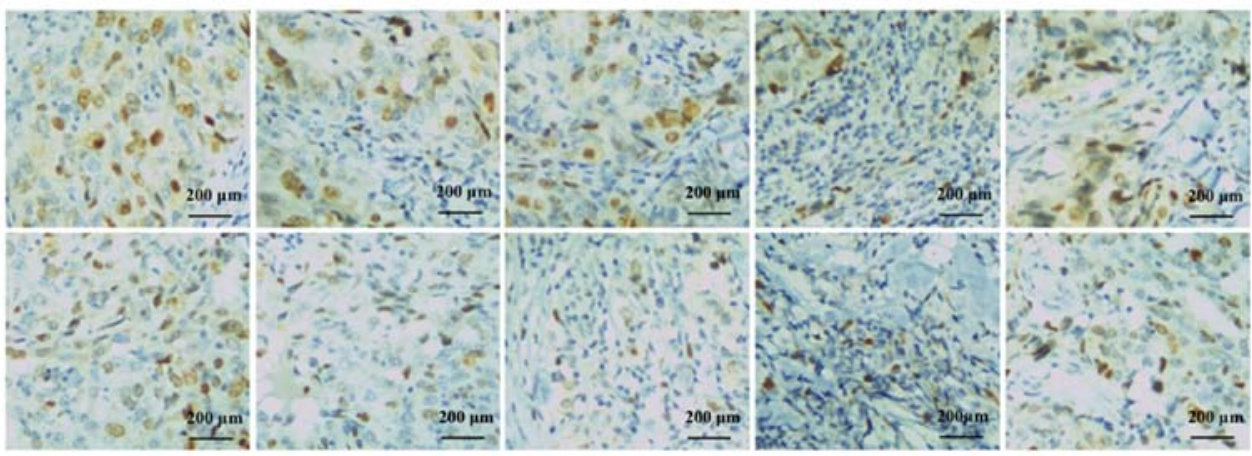

B
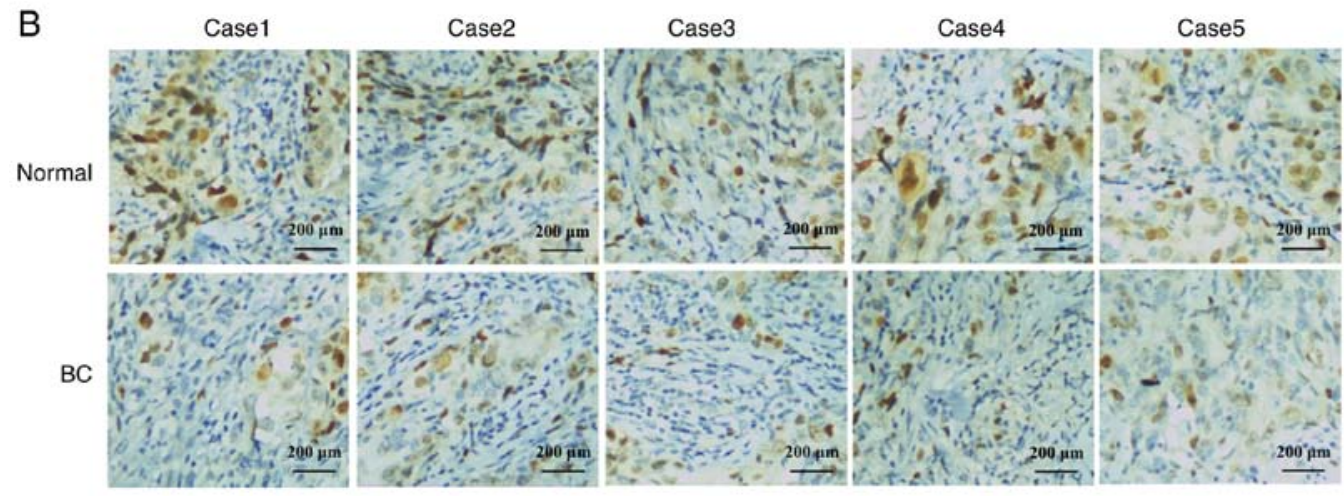

Case2
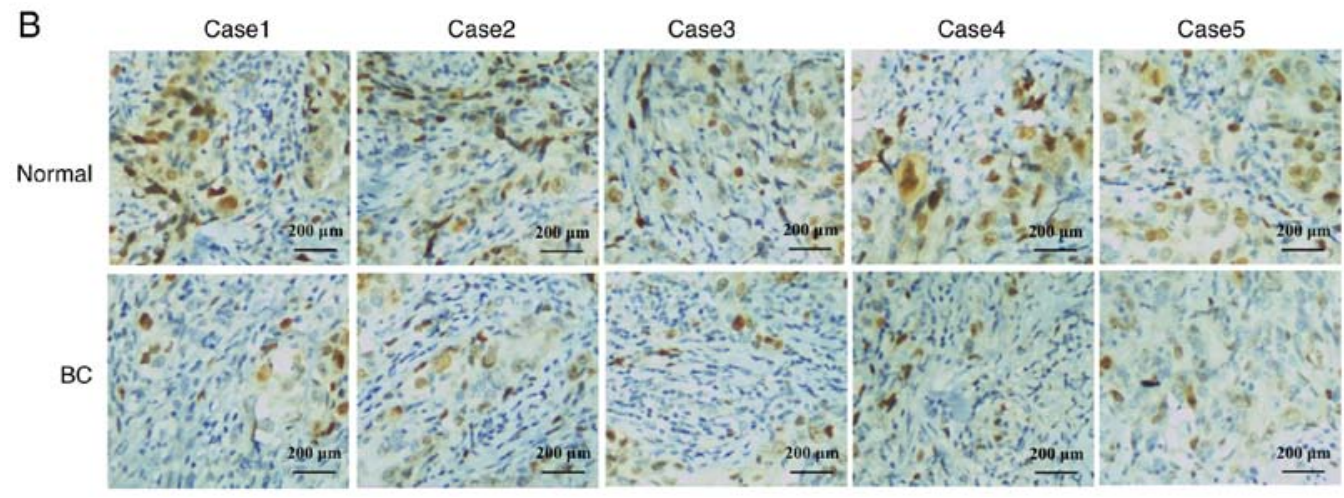

Case5

C

Case1

Case2

Case3

Case 4

Case5
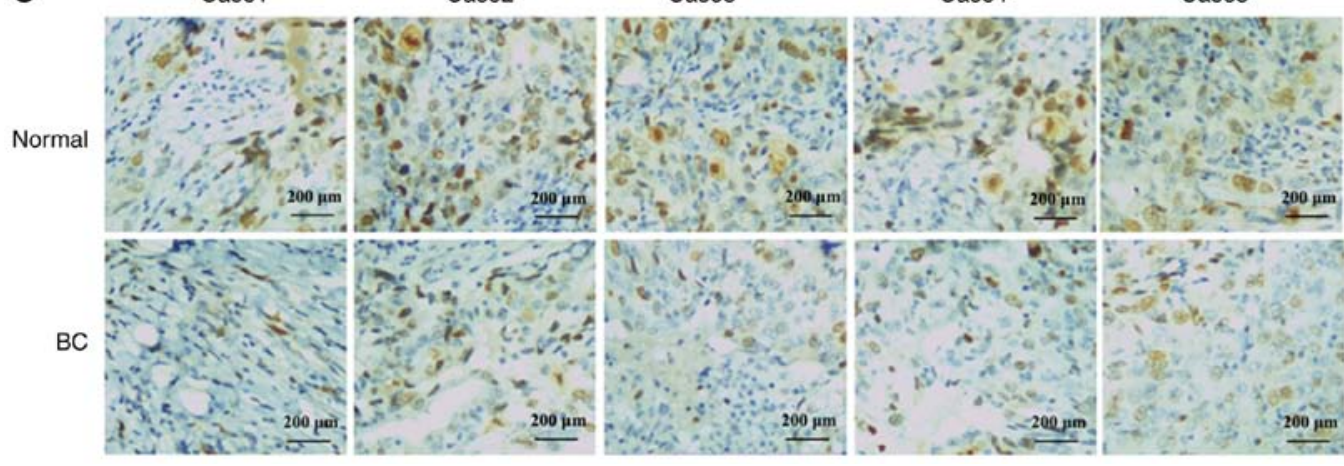

Figure 1. PDCD4 protein was detected in three sets of normal and breast cancer tissues using immunohistochemistry. (A) PDCD4 protein expression was detected in five normal and five BC tissues using immunohistochemistry, and decreased substantially in BC tissues compared with normal control tissues. (B) PDCD4 protein expression was determined by immunohistochemistry in five normal and five BC tissues, and was notably decreased in BC tissues. (C) PDCD4 protein expression was analyzed in five normal and five BC tissues by immunohistochemistry, but was downexpressed in BC tissues. BC, breast cancer; PDCD4, programmed cell death 4.

immunohistochemistry results are presented. PDCD4 protein expression was detected in three sets of five normal and five BC tissues in each set, using immunohistochemistry (Fig. 1A-C), and was decreased substantially in $\mathrm{BC}$ tissues compared with normal control tissues.

Expression of miR-421 in BC tissues and cell lines. RT-qPCR analysis was performed to assess the expression of miR-421 in BC tissues, Hs578bst cells, MCF-7 cells and MDA-MB-231 cells (Fig. 2A and B). The expression of miR-421 was significantly increased in the $\mathrm{BC}$ tissues and cells compared with the normal controls. By contrast, the protein expression of PDCD4 was markedly downregulated in $\mathrm{BC}$ cells compared with the controls (Fig. 2C and D). These results suggested that the overexpression of miR-421 was associated with the downregulation of PDCD4 in BC.
$P D C D 4$ is a direct target gene of $m i R-421$. PDCD4 was found as a potential target gene of miR-421. Luciferase reporter assays were performed to further confirm whether PDCD4 is a direct target of miR-421. The 3'-UTR of PDCD4 mRNAs, including putative binding sites of miR-421 together with their corresponding mutated sequences, were cloned into vectors and co-transfected into $\mathrm{BC}$ cells with miR-421 mimics, inhibitors or mock miRNA (Fig. 3A). Transfection with miR-421 mimics suppressed the luciferase activity significantly in MCF-7 cells (Fig. 3B) and MDA-MB-231 cells (Fig. 3C); by contrast, miR-421 inhibitors significantly enhanced the luciferase activity in MCF-7 cells (Fig. 3B) and MDA-MB-231 cells (Fig. 3C). The functions of the miR-421 mimics and inhibitors were abrogated when mutated 3'-UTR PDCD4-vector constructs were used, suggesting that miR-421 directly targets the 3'-UTRs of PDCD4. 

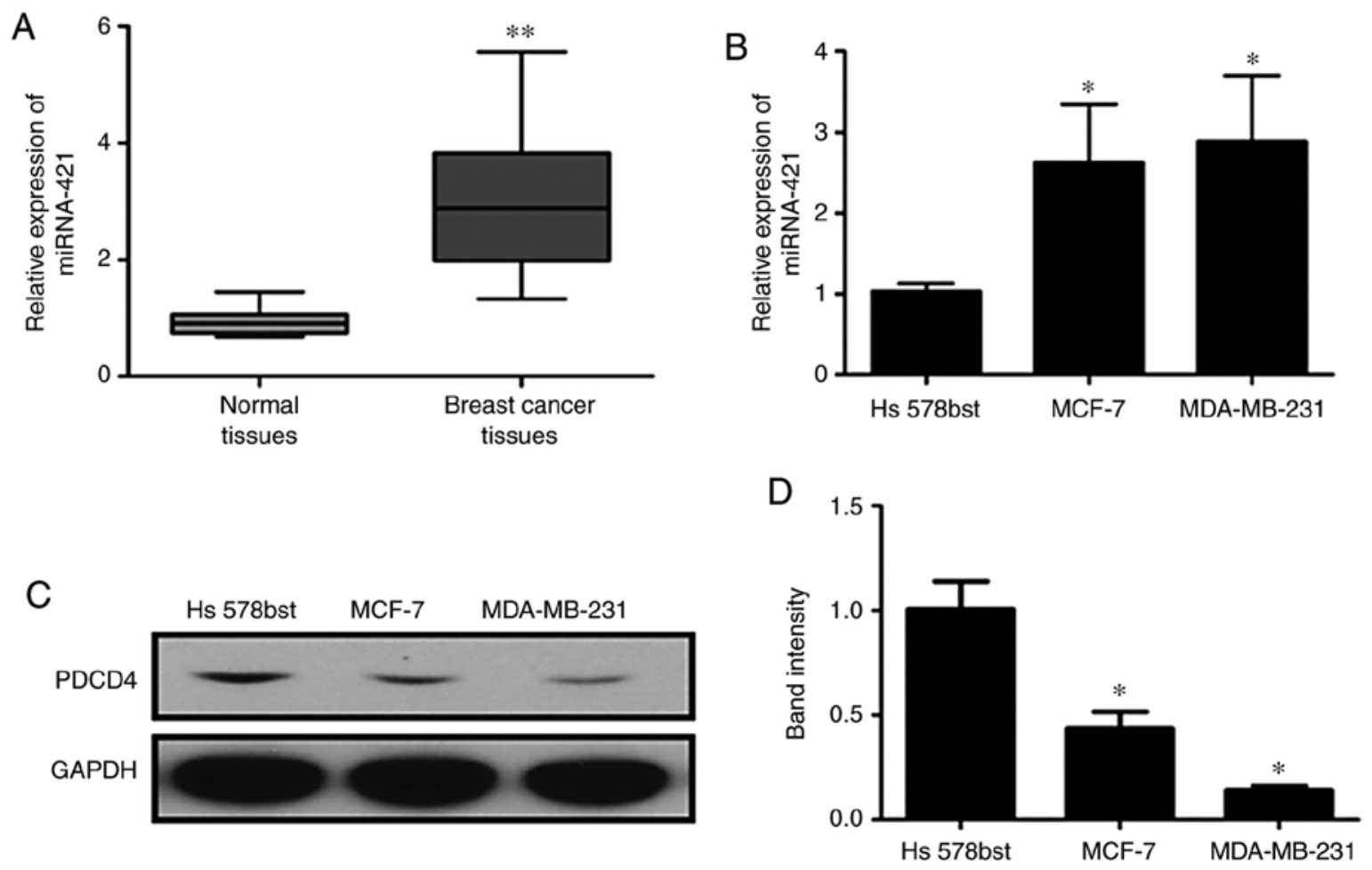

Figure 2. Levels of miR-421 and expression of PDCD4 in BC. miR-421 levels were determined in BC tissues, MCF-7 cells and MDA-MB-231 cells, and the expression of PDCD4 was determined in MCF-7 cells and MDA-MB-231 cells. (A) Relative expression of miR-421 in 52 paired BC and normal tissues. (B) Relative expression of miR-421 in Hs578bst, MCF-7 and MDA-MB-231 cells. (C) Protein expression and PDCD4 in Hs578bst, MCF-7 and MDA-MB-231 cells was assessed using western blot analysis and (D) quantified. U6 was used as an endogenous control. ${ }^{*} \mathrm{P}<0.05$ and ${ }^{* *} \mathrm{P}<0.01$ vs. normal/control groups. $\mathrm{BC}$, breast cancer; miR, microRNA; PDCD4, programmed cell death 4 .

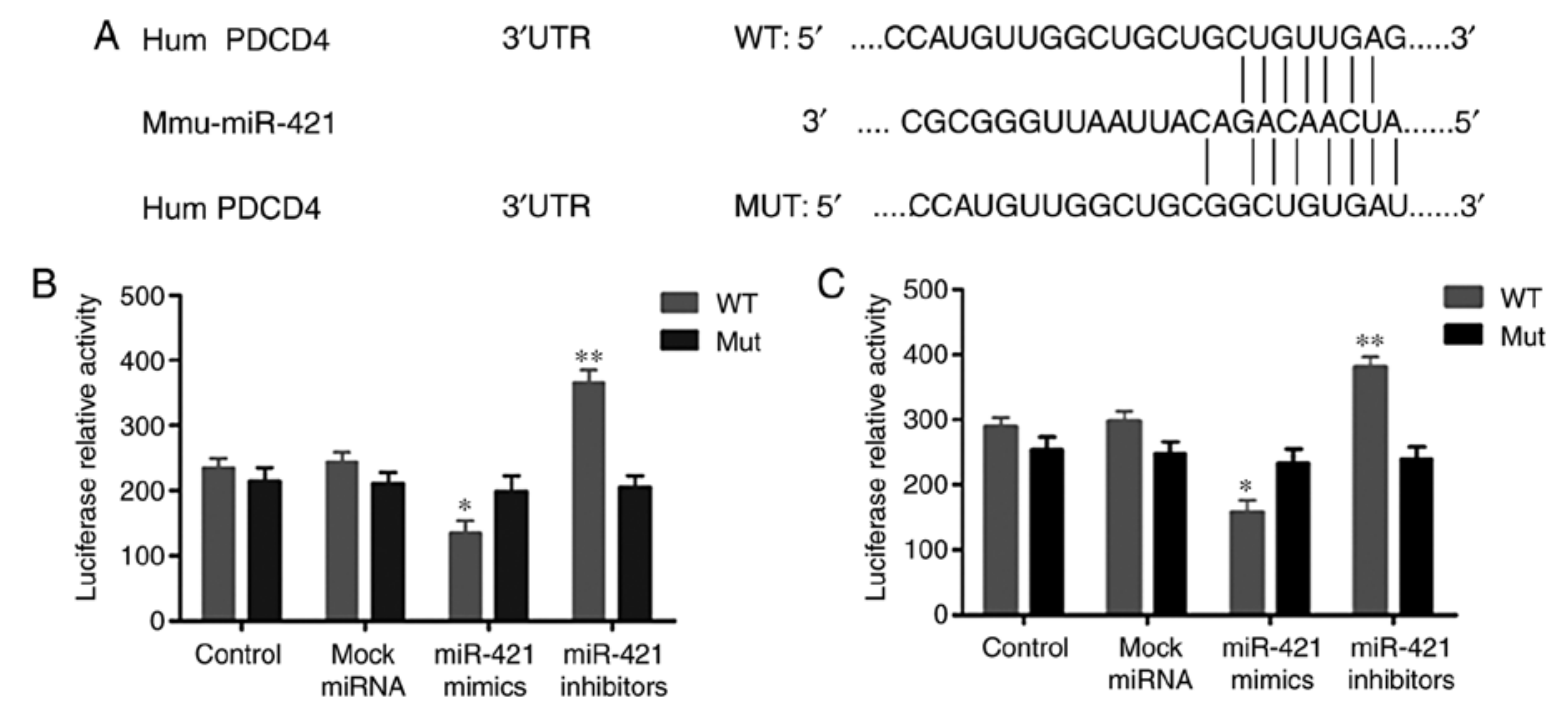

Figure 3. PDCD4 is a direct target of miR-421. (A) A luciferase activity assay confirmed that miR-421 directly binds to PDCD4, as predicted by TargetScan. (B) Overexpression of miR-421 significantly inhibited the luciferase activity of PDCD4 in MCF-7 cells. (C) Luciferase activity of PDCD4 in MDA-MB-231 cells transfected with miR-421 inhibitors was significantly increased. ${ }^{*} \mathrm{P}<0.05$ and ${ }^{* *} \mathrm{P}<0.01$ vs. normal/control groups. miR, microRNA; Hum, human; PDCD4, programmed cell death 4; WT, wild-type; Mut, mutant.

miR-421 promotes $B C$ cell proliferation in vitro. The results revealed that transfection with miR-421 mimics enhanced the proliferation of Hs578bst (Fig. 4A), MCF-7 (Fig. 4B) and MDA-MB-231 (Fig. 4C) cells; however, transfection with miR-421 inhibitors had the opposite effect. These results suggested that the overexpression of miR-421 accelerates BC cell proliferation in vitro.
miR-421 promotes the migration and invasion of BC cells. The Transwell results revealed that the overexpression of miR-421 significantly promoted the migration of MCF-7 and MDA-MB-231 cells, whereas miR-421 knockdown inhibited cell migration (Fig. 5A). The Matrigel assay revealed that the invasive abilities of the MCF-7 and MDA-MB-231 cells were enhanced following transfection with miR-421 mimics 

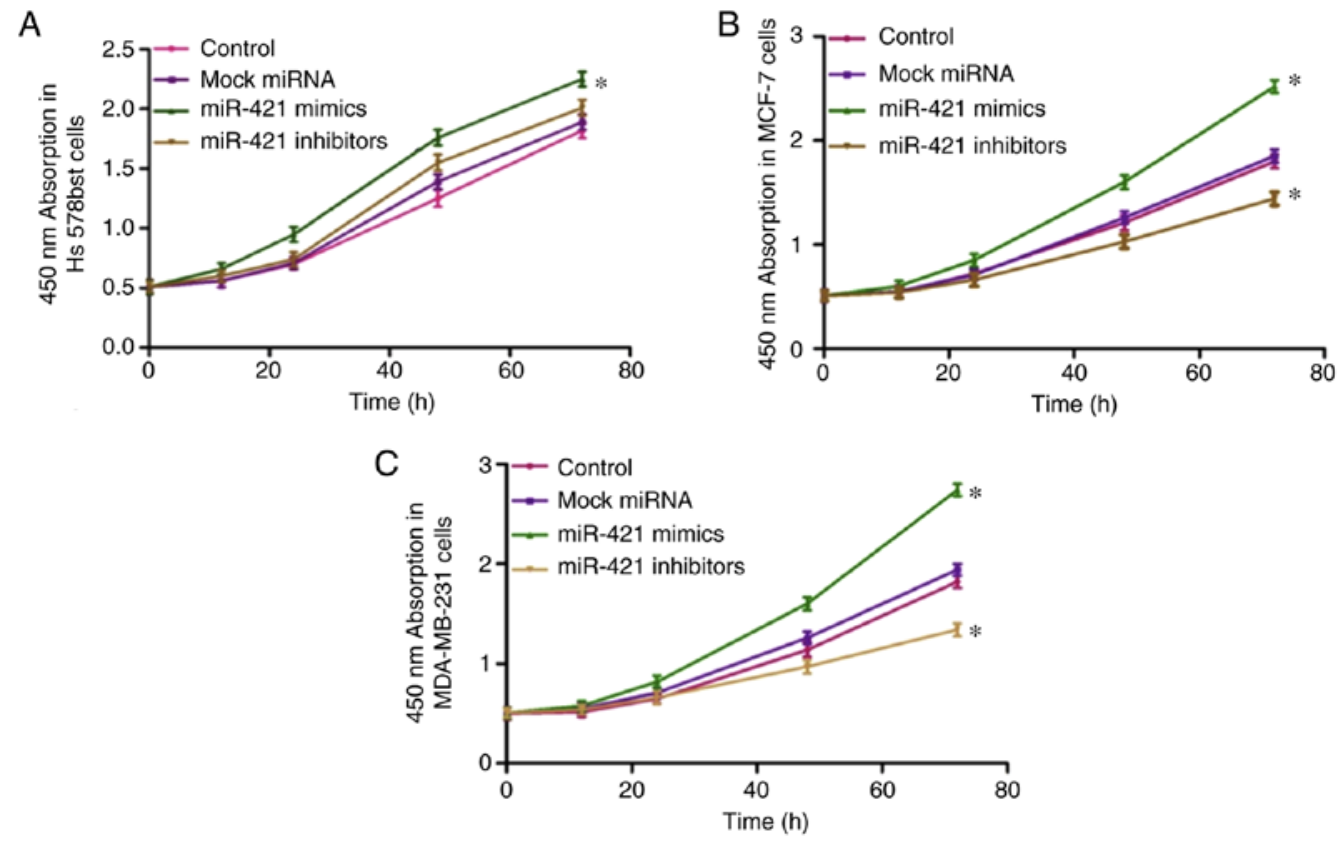

Figure 4. miR-421 promotes the proliferation of MCF-7 and MDA-MB-231 cells in vitro as analyzed using a Cell Counting Kit-8 assay. (A) miR-421 inhibitors promoted the proliferation of normal Hs578bst cells compared with other groups. (B) MCF-7 proliferation was enhanced following transfection with miRNA-421 mimics compared with the control groups. (C) MDA-MB-231 cell growth was regulated by miR- 421 . " $\mathrm{P}<0.05 \mathrm{vs.} \mathrm{normal/control} \mathrm{groups.} \mathrm{miR,}$ microRNA.

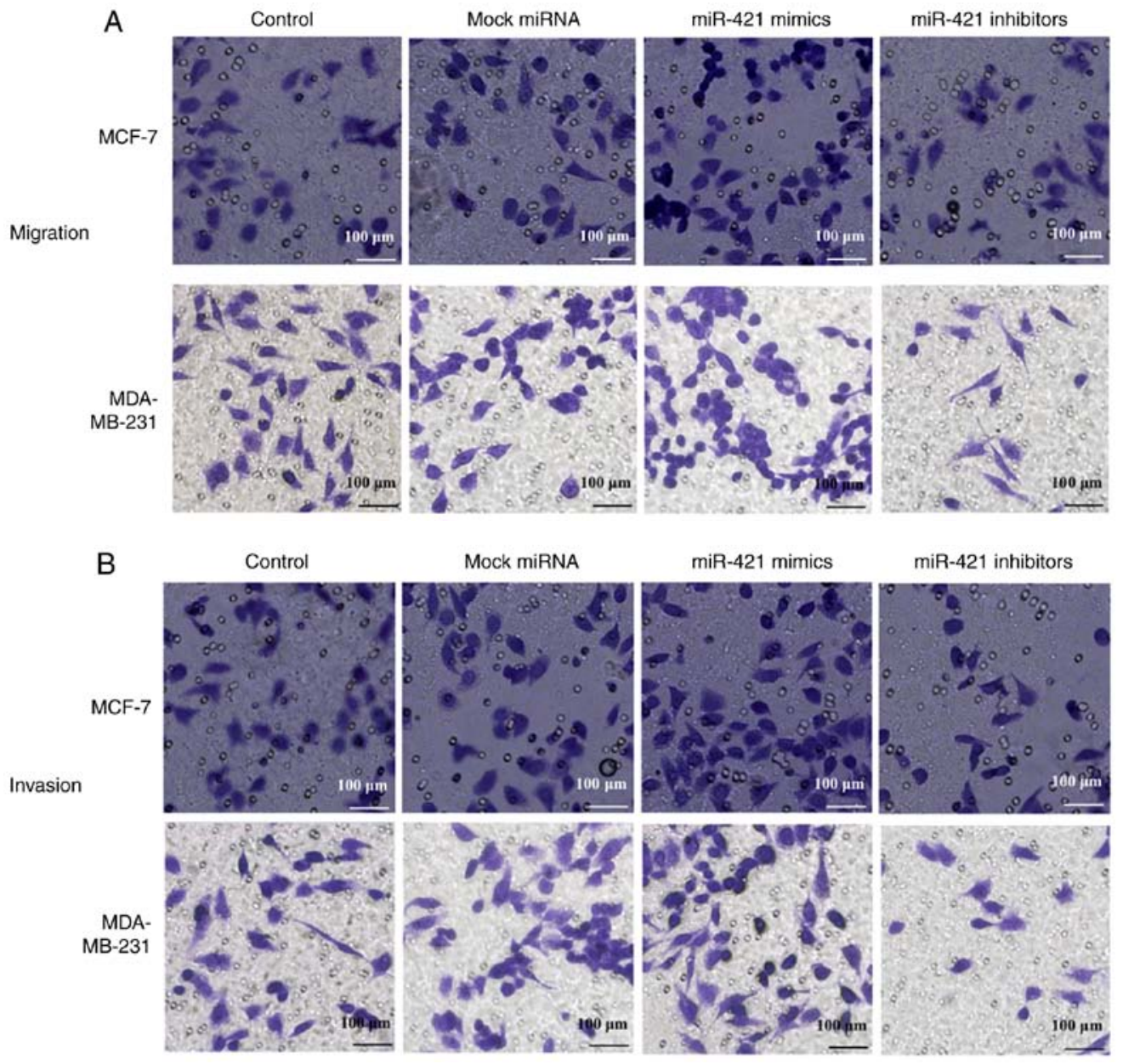

Figure 5. Transwell results show miR-421 promotes the migration and the invasion of breast cancer cells. (A) MCF-7 and MDA-MB-231 cell migration increased following transfection with miR-421 mimics, but was suppressed in the miR-421 inhibitors group compared with the control or mock miRNA groups. (B) MCF-7 and MDA-MB-231 cell invasion was enhanced following transfection with miR-421 mimics, whereas the opposite was observed following transfection with miR-421 inhibitors. Images were captured using an inverted microscope (magnification, x200). miR, microRNA. 

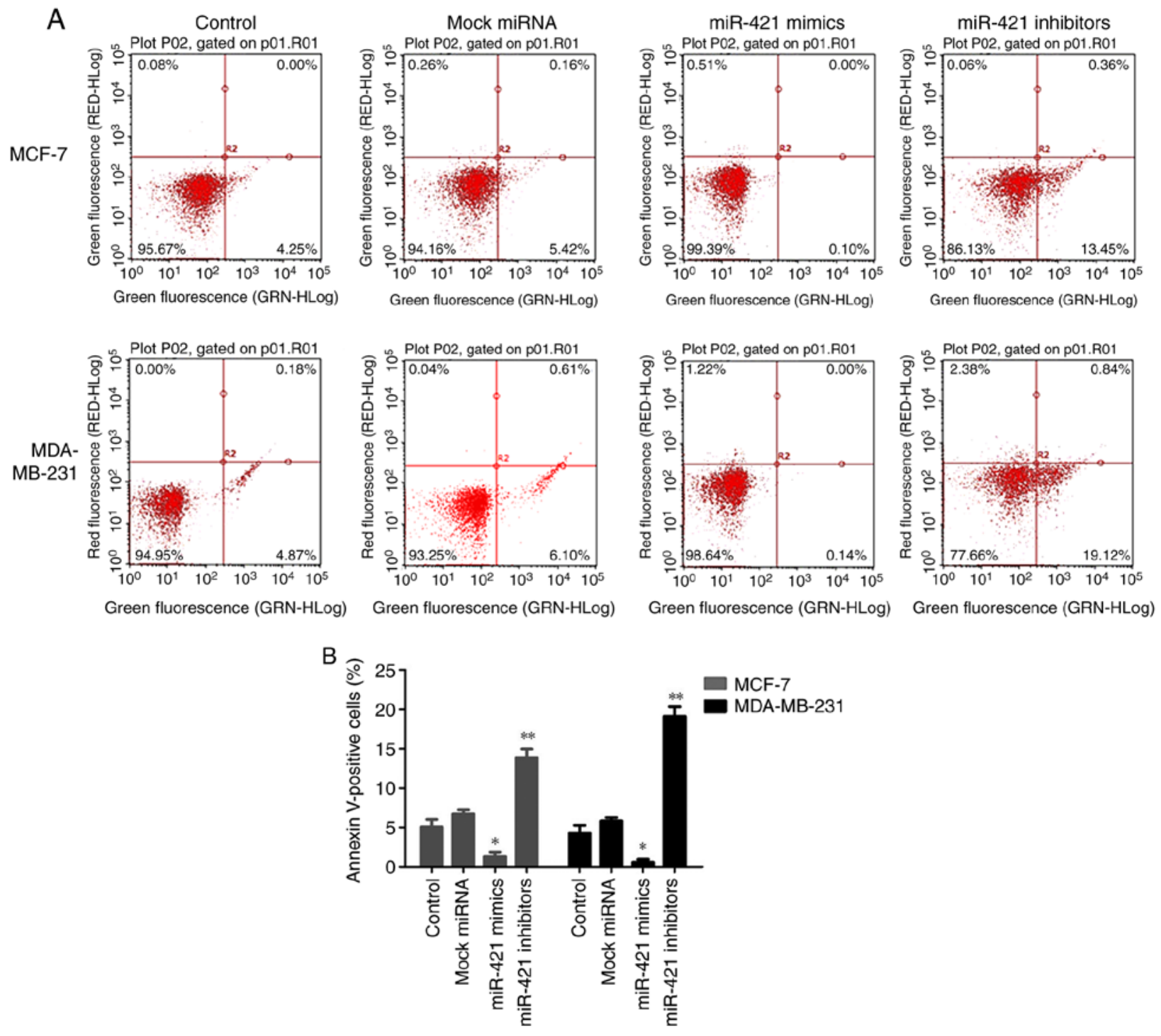

Figure 6. Effects of expression of miR-421 on breast cancer cell apoptosis. Apoptosis was assessed using flow cytometry. (A) MCF-7 and MDA-MB-231 cell apoptosis was assessed following transfection with miR-421 mimics and inhibitors. (B) Statistical analysis of MCF-7 and MDA-MB-231 cell apoptosis ${ }^{*} \mathrm{P}<0.05$ and ${ }^{* *} \mathrm{P}<0.01$ vs. control groups. miR, microRNA.

and downregulated by miR-421 inhibitors (Fig. 5B). These results suggested that the expression of miR-421 increases the motility of MCF-7 and MDA-MB-231 BC cells.

miR-421 influences BC cell apoptosis. The flow cytometry results suggested that the number of apoptotic MCF-7 and MDA-MB-231 cells (Fig. 6A) was significantly increased following transfection with miR-421 inhibitors compared with the control group (Fig. 6B), suggesting that miR-421 affects the apoptosis of MCF-7, MDA-MB-231 cells via regulating PDCD4.

miR-421 regulates the protein expression of PDCD4. The RT-qPCR and western blot analyses revealed that the expression of miR-421 was increased in MCF-7 and MDA-MB-231 cells transfected with miR-421 mimics, but decreased in cells transfected with miR-421 inhibitors (Fig. 7A). Furthermore, the overexpression of miRNA-421 suppressed the expression of PDCD4 at the mRNA (Fig. 7B) and protein (Fig. 7C and D) levels in MCF-7 and MDA-MB-231 cells. By contrast, miR-421 knockdown upregulated the mRNA and protein levels of PDCD4, suggesting that PDCD4 is directly regulated by miR-421 and may function as an anticancer gene.

\section{Discussion}

miRNAs have previously been reported to be associated with key developmental pathways, and various miRNA disorders contribute to a number of human ailments, including inflammatory diseases, infection, developmental disabilities and cancer (25). Abnormal miRNA expression has been reported in a number of types of cancer, with miRNAs serving tumor-suppressive or oncogenic roles to modulate tumor cell growth, cell cycle progression, migration and metastasis (26). miR-421, which is located in Xq13.2, has been reported to be involved in the post-transcriptional regulation of gene expression by affecting the stability and translation of genes in multicellular organisms, while regulating the expression of multiple tumor-promoting genes (27). Previous studies have shown that miR-421 is significantly overexpressed in gastric cancer tissues and promotes gastric cancer cell proliferation by 
A

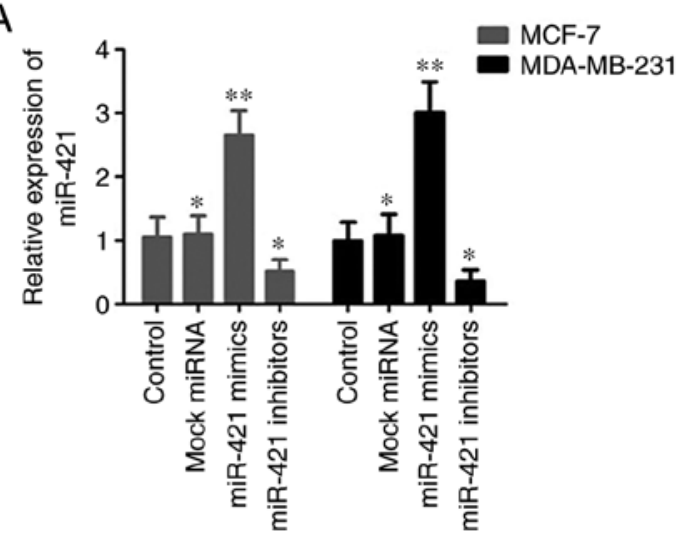

B
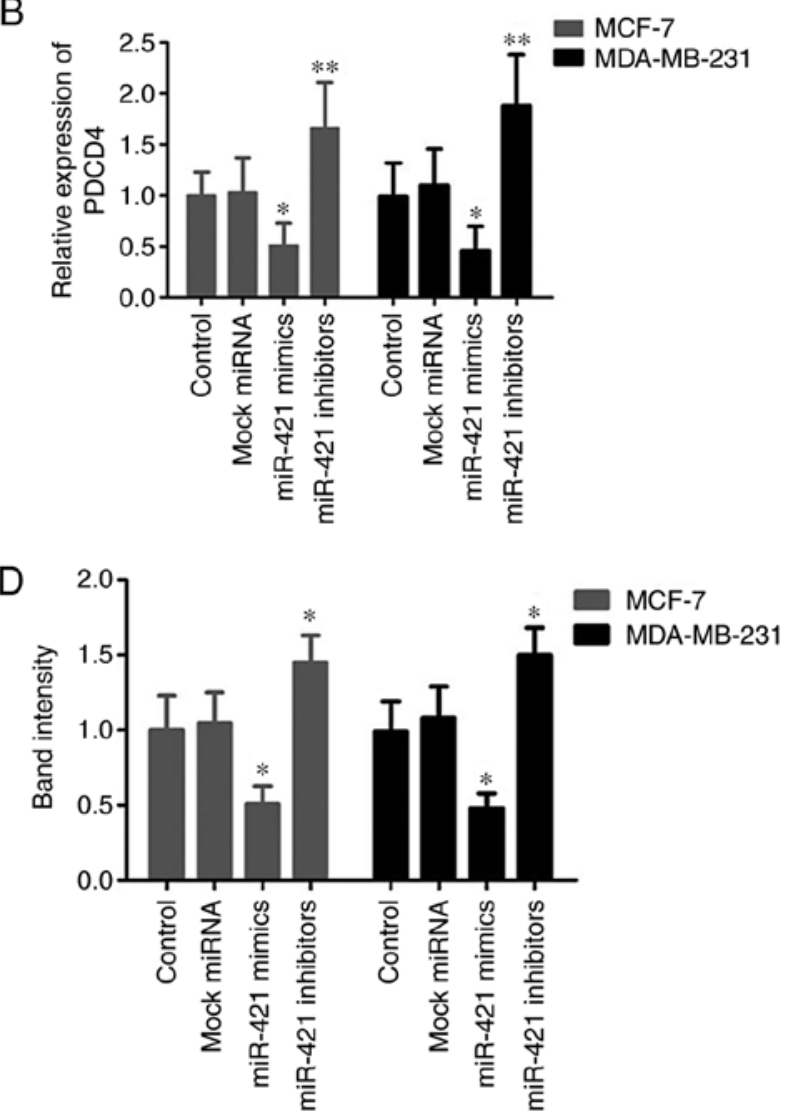

Figure 7. Assessment of the expression of PDCD4 in breast cancer cell lines using RT-qPCR and western blot analysis. (A) miR-421 and (B) PDCD4 gene expression were measured in MCF-7 and MDA-MB-231 cells transfected with mock miRNA, miR-421 mimics and miR-421 inhibitors using RT-qPCR analysis. (C) Protein expression of PDCD4 was assessed in MCF-7 and MDA-MB-231 cells transfected with miR-421 mimics and miR-421 inhibitors using western blot analysis with (D) quantification of results. ${ }^{*} \mathrm{P}<0.05$ and ${ }^{* *} \mathrm{P}<0.01$ vs. normal/control groups. miR, microRNA; PDCD4, programmed cell death 4; RT-qPCR, reverse transcription-quantitative polymerase chain reaction.

downregulating the expression of caspase-3 (28). Furthermore, miR-421 may act as a tumor promoter in pancreatic cancer by targeting DPC4/Smad4 (29).

In the present study, it was found that miR-421 was significantly upregulated in $\mathrm{BC}$ tissues and cells compared with normal controls. However, miR-421 knockdown inhibited the proliferation, migration and invasion abilities of $\mathrm{BC}$ cells, and promoted apoptosis. PDCD4 was predicted as a target gene of miR-421 using TargetScan software. PDCD4 is a tumor suppressor protein, which is able to induce apoptosis in tumor cells $(30,32)$ by binding to the translation initiation factor eukaryotic initiation factor-4A, inhibiting RNA-helicase activity and in turn suppressing protein translation (33). Furthermore, PDCD4 is able to inhibit activator protein-1-mediated transactivation (34) and induce the expression of cyclin-dependent kinase inhibitor p21 (35). PDCD4 is involved in tumorigenesis and tumor progression $(36,37)$ and is downregulated in $\mathrm{BC}$ (38). These results suggest that miRNA-421 may function as an onco-miRNA in BC cells by regulating PDCD4.

The results of the present study indicated that miR-421 regulates the proliferation, migration, invasion and apoptosis of BC cells by targeting PDCD4. PDCD4 is important in a number of cellular physiological activities. In conclusion, PDCD4 may represent a novel therapeutic target for BC, and miR-421 may be used as a potential treatment for BC.

\section{Acknowledgements}

Not applicable.

\section{Funding}

No funding was received.

\section{Availability of data and materials}

All data generated or analyzed during this study are included in this published article.

\section{Authors' contributions}

YW and ZL completed all experiments and wrote the manuscript. JS designed and guided all experiments in the paper. In addition, all authors revised the manuscript. All authors read and approved the final manuscript.

\section{Ethics approval and consent to participate}

All protocols were approved by the Ethics Committee of the Second Affiliated Hospital of Xi'an Medical University (Xi'an, China) and written informed consent was provided by all participants. 


\section{Patient consent for publication}

All patients involved in the present study consented to the publication of their data.

\section{Competing interests}

The authors declare that they have no competing interests.

\section{References}

1. Siegel R, Naishadham D and Jemal A: Cancer statistics, 2013. CA Cancer J Clin 63: 11-30, 2013.

2. Bandyopadhyay S Bluth MH and Ali-Fehmi R: Breast carcinoma: Updates in molecular profiling 2018. Clin Lab Med 38: 401-420, 2018

3. Cheng CW, Yu JC, Hsieh YH, Liao WL, Shieh JC, Yao CC, Lee HJ, Chen PM, Wu PE and Shen CY: Increased cellular levels of microRNA-9 and microRNA-221 correlate with cancer stemness and predict poor outcome in human breast Cancer. Cell Physiol Biochem 48, 2205-2218, 2018.

4. Mansoori B, Mohammadi A, Shirjang S and Baradaran B: HMGI-C suppressing induces P53/caspase9 axis to regulate apoptosis in breast adenocarcinoma cells. Cell Cycle 15: 2585-2592, 2016

5. Mansoori B, Mohammadi A, Goldar S, Shanehbandi D, Mohammadnejad L, Baghbani E, Kazemi T, Kachalaki S and Baradaran B: Silencing of high mobility group isoform IC (HMGI-C) enhances paclitaxel chemosensitivity in breast adenocarcinoma cells (MDA-MB-468): Adv Pharm Bull 6: 171-177, 2016.

6. Raval GN, Bharadwaj S, Levine EA, Willingham MC, Geary RL, Kute T and Prasad GL: Loss of expression of tropomyosin-1, a novel class II tumor suppressor that induces anoikis, in primary breast tumors. Oncogene 22: 6194-203, 2003.

7. Volinsky N, McCarthy CJ, von Kriegsheim A, Saban N, Okada-Hatakeyama M, Kolch W and Kholodenko BN: Signalling mechanisms regulating phenotypic changes in breast cancer cells. Biosci Rep 35: e00178, 2015.

8. Sauter ER: Breast cancer prevention: Current approaches and future Directions. Eur J Breast Health 14: 64-71, 2018.

9. Zhuo D and Li X: Biological roles of aberrantly expressed glycosphingolipids and related enzymes in human cancer development and progression. Front Physiol 9: 466, 2018.

10. Bronchud MH, Tresserra F and Zantop BS: Epigenetic changes found in uterine decidual and placental tissues can also be found in the breast cancer microenvironment of the same unique patient: description and potential interpretations. Oncotarget 9: 6028-6041, 2017.

11. Jovanovic J, Rønneberg JA, Tost J and Kristensen V: The epigenetics of breast cancer. Mol Oncol 4: 242-254, 2010.

12. Weidle UH, Dickopf S, Hintermair C, Kollmorgen G, Birzele F and Brinkmann U: The role of micro RNAs in breast cancer metastasis: Preclinical validation and potential therapeutic targets. Cancer Genomics Proteomics 15: 17-39, 2018.

13. Byler S, Goldgar S, Heerboth S, Leary M, Housman G, Moulton K and Sarkar S: Genetic and epigenetic aspects of breast cancer progression and therapy. Anticancer Res 34: 1071-1077, 2014.

14. Dworkin AM, Huang THM and Toland AE: Epigenetic alterations in the breast: Implications for breast cancer detection, prognosis and treatment. Semin Cancer Biol 19: 165-171, 2009.

15. Hosseinahli N, Aghapour M, Duijf PHG and Baradaran B: Treating cancer with microRNA replacement therapy: A literature review. J Cell Physiol 233: 5574-5588, 2018.

16. Sieuwerts AM, Mostert B, Bolt-de Vries J, Peeters D, de Jongh FE, Stouthard JM, Dirix LY, van Dam PA, Van Galen A, de Weerd V, et al: mRNA and microRNA expression profiles in circulating tumor cells and primary tumors of metastatic breast cancer patients. Clin Cancer Res 17: 3600-3618, 2011.

17. Ranji N, Sadeghizadeh M, Karimipoor M, Shokrgozar MA and Ebrahimzadeh-Vesal R: AKT family and miRNAs expression in IL-2 induced CD4(+) T cells. Iran J Basic Med Sci 17: 886-894, 2014.

18. Blondal T, Jensby Nielsen S, Baker A, Andreasen D, Mouritzen P, Wrang Teilum $M$ and Dahlsveen IK: Assessing sample and miRNA profile quality in serum and plasma or other biofluids. Methods 59: S1-S6, 2013
19. Ranji N, Sadeghizadeh M, Shokrgozar MA, Bakhshandeh B, Karimipour M, Amanzadeh A and Azadmanesh K: MiR-17-92 cluster: An apoptosis inducer or proliferation enhancer. Mol Cell Biochem 380: 229-238, 2013.

20. Sarkar FH, Li Y, Wang Z, Kong D and Ali S: Implication of microRNAs in drug resistance for designing novel cancer therapy. Drug Resist Updat 13: 57-66, 2010.

21. Meng D, Yang S, Wan X, Zhang Y, Huang W, Zhao P, Li T, Wang L, Huang Y, Li T and Li Y: A transcriptional target of androgen receptor, miR-421 regulates proliferation and metabolism of prostate cancer cells. Int J Biochem Cell Biol 73: 30-40, 2016.

22. Pan Y, Jiao G, Wang C, Yang J and Yang W: MicroRNA-421 inhibits breast cancer metastasis by targeting metastasis associated 1. Biomed Pharmacother 83: 1398-1406, 2016.

23. Jiang Z, Guo J, Xiao B, Miao Y, Huang R, Li D and Zhang Y: Increased expression of miR-421 in human gastric carcinoma and its clinical association. J Gastroenterol 45: 17-23, 2010.

24. Livak KJ and Schmittgen TD: Analysis of relative gene expression data using real-time quantitative PCR and the $2-\Delta \Delta \mathrm{CT}$ method. Methods 25: 402-408, 2001.

25. Mehrgou A and Akouchekian M: Therapeutic impacts of microRNAs in breast cancer by their roles in regulating processes involved in this disease. J Res Med Sci 22: 130, 2017.

26. Petrovic $\mathrm{N}$ and Ergun S: miRNAs as potential treatment targets and treatment options in cancer. Mol Diagn Ther 22: 157-168, 2018.

27. Wu J, Li G, Yao Y, Wang Z, Sun W and Wang J: MicroRNA-421 is a new potential diagnosis biomarker with higher sensitivity and specificity than carcinoembryonic antigen and cancer antigen 125 in gastric cancer. Biomarker 20: 58-63, 2015.

28. Wu JH, Yao YL, Gu T, Wang ZY, Pu XY, Sun WW, Zhang X, Jiang YB and Wang JJ: MiR-421 regulates apoptosis of BGC-823 gastric cancer cells by targeting caspase-3. Asian Pac J Cancer Prev 15: 5463-5468, 2014.

29. Hao J, Zhang S, Zhou Y, Liu C, Hu X and Shao C: MicroRNA-421 suppresses DPC4/Smad4 in pancreatic cancer. Biochem Biophys Res Commun 406: 552-557, 2011.

30. Lankat-Buttgereit B and Göke R: The tumour suppressor Pdcd4 recent advances in the elucidation of function and regulation. Biol Cell 101: 309-317, 2009.

31. Göke R, Gregel C, Göke A, Arnold R, Schmidt H and Lankat-Buttgereit B: Programmed cell death protein 4 (PDCD4) acts as a tumor suppressor in neuroendocrine tumor cells. Ann N Y Acad Sci 1014: 220-221, 2004.

32. Yang HS, Jansen AP, Komar AA, Zheng X, Merrick WC, Costes S, Lockett SJ, Sonenberg N and Colburn NH: The transformation suppressor Pdcd4 is a novel eukaryotic translation initiation factor 4A binding protein that inhibits translation. Mol Cell Biol 23: 26-37, 2003.

33. Yang HS, Cho MH, Zakowicz H, Hegamyer G, Sonenberg $\mathrm{N}$ and Colburn NH: A novel function of the MA-3 domains in transformation and translation suppressor Pdcd4 is essential for its binding to eukaryotic translation initiation factor 4A. Mol Cell Biol 24: 3894-3906, 2004.

34. Yang HS, Jansen AP, Nair R, Shibahara K, Verma AK, Cmarik JL and Colburn NH: A novel transformation suppressor, Pdcd4, inhibits AP-1 transactivation but not NF-kappaB or ODC transactivation. Oncogene 20: 669-676, 2011.

35. Goke R, Barth P, Schmidt A, Samans B and Lankat-Buttgereit B: Programmed cell death protein 4 suppresses CDK1/cdc2 via induction of p21(Waf1/Cip1). Am J Physiol Cell Physiol 287: C1541-C1546, 2004.

36. Zhang Z, Wang J, Li J, Wang X and Song W: MicroRNA-150 promotes cell proliferation, migration, and invasion of cervical cancer through targeting PDCD4. Biomed Pharmacother 97: 511-517, 2018

37. Schmid T, Jansen AP, Baker AR, Hegamyer G, Hagan JP and Colburn NH: Translation inhibitor Pdcd4 is targeted for degradation during tumor promotion. Cancer Res 68: 1254-1260, 2008.

38. Wen YH, Shi X, Chiriboga L, Matsahashi S, Yee H and Afonja O: Alterations in the expression of PDCD4 in ductal carcinoma of the breast. Oncol Rep 18: 1387-1393, 2007.

This work is licensed under a Creative Commons Attribution-NonCommercial-NoDerivatives 4.0 International (CC BY-NC-ND 4.0) License. 